\title{
Avaliação imuno-histoquímica de 100 casos de metástases encefálicas e correlação com 0 sítio primário do tumor
}

Primeira submissão em 16/05/10 Última submissão em 30/08/10 Aceito para publicação em 09/10/10 Publicado em 20/02/11

\author{
Immunohistochemical evaluation of 100 cases of encephalic metastases and correlation with primary \\ site of the tumor
}

Eduardo Cambruzzi'; Karla Lais Pêgas²; Márcio Balbinotti Ferrari ${ }^{3}$

unitermos
Neoplasias encefálicas
Neoplasias do sistema
nervoso central
Patologia
Imuno-histoquímica
Metástase neoplásica

\section{resumo}

Introdução: As metástases encefálicas correspondem a massas intracranianas avaliadas tanto em procedimentos cirúrgicos quanto em necropsias. Em geral, as metástases comprometem os hemisférios cerebrais de adultos com o diagnóstico prévio de um carcinoma. Usualmente são encontradas como lesões sólidas de crescimento expansivo, sendo o pulmão e a mama os sítios primários mais frequentes. Objetivo: Determinar o sítio primário, a topografia, o tipo histológico e o perfil imuno-histoquímico de metástases encefálicas. Método: Foram avaliados 100 casos distintos de metástases intraparenquimatosas do encéfalo, previamente analisadas entre 1995 e 2009 no Hospital Conceição de Porto Alegre, sendo determinados os tipos histológicos envolvidos e a topografia. Os casos selecionados foram submetidos à técnica imuno-histoquímica a fim de estimar o sítio primário destas lesões. Resultados: A idade média correspondeu a 58,7 anos, sendo encontrados 61 casos (61\%) no sexo masculino. O tipo histológico mais comum foi o adenocarcinoma (56 casos [56\%]), sendo os hemisférios cerebrais (78 casos [78\%]) as topografias mais acometidas. O pulmão (29\%), a mama (16\%), o tecido hematopoiético (14\%) e o rim (12\%) corresponderam aos principais sítios primários. A análise estatística não determinou associação entre o tipo histológico ou o sítio primário e a topografia $(p=0,125)$. Foi encontrada uma concordância de $95 \%$ entre o perfil imuno-histoquímico e a informação clínica do sítio primário. Conclusão: $\mathrm{O}$ conjunto dos achados morfológicos associado ao estudo imuno-histoquímico de uma lesão metastática do encéfalo pode sugerir o sítio primário em vários casos, sendo necessária, para isso, a correta escolha do painel de anticorpos.

Introduction: Encephalic metastases correspond to intracranial masses evaluated in both surgical procedures and autopsies. Overall, metastases involve the cerebral hemispheres of adults with a previous diagnosis of carcinoma. They are commonly found as solid lesions with an expansive growth, whose most frequent primary sites are lungs and breasts. Objective: To determine the primary site, topography, histology and immunohistochemical profile of encephalic metastases. Method: 100 cases of intraparenchymal brain metastases, which had been previously analyzed between 1995 and 2009 at Hospital Conceição from Porto Alegre, were evaluated. The topography and the histological types involved were determined. The selected cases were submitted to immunohistochemical analysis to assess the primary site of these lesions. Results: The mean age was 58.7 years old and 61 cases (59.89\%) were found in males. The most common histological type was adenocarcinoma (56 cases-56\%) and the most affected topography was the cerebral hemispheres (78 cases, 78\%). The main primary sites were lungs (29\%), breasts (16\%), hematopoietic tissue (14\%) and kidneys (12\%). Statistical analysis did not determine association between histological type or primary site in relation to topography $(\mathrm{p}=0.125)$. There was a concordance of $95 \%$ between the immunohistochemical profile and clinical information from the primary site. Conclusion: The set of morphological findings associated with immunohistochemical study of an encephalic metastatic lesion may suggest the primary site in several cases, which, therefore, requires the appropriate choice of antibody panel.

key words

Brain neoplasms

Central nervous system neoplasms

Pathology

Immunohistochemistry

Neoplastic metastasis

1. Doutor em Anatomia Patológica e Citopatologia; professor regente da disciplina de Patologia da Universidade Luterana do Brasil (ULBRA).

2. Mestranda em Patologia; médica patologista da Santa Casa de Porto Alegre.

3. Acadêmico de Medicina pela ULBRA.

Pesquisa elaborada e realizada no Laboratório de Anatomia Patológica e Citopatologia do Crupo Hospitalar Conceição de Porto Alegre. 


\section{Introdução}

As metástases correspondem a aproximadamente 25\% dos casos de tumores do sistema nervoso central (SNC), com uma incidência estimada em 11:100.000 na população em geral. As metástases encefálicas representam causa importante de morbidade e mortalidade para os pacientes com neoplasias malignas. Os sítios primários mais comuns em adultos, em ordem decrescente, são pulmão (35\% a $40 \%$ - carcinoma de pequenas células e adenocarcinoma), mama ( $14 \%$ a $18 \%$ - carcinoma ductal infiltrante), melanoma cutâneo (10\%) e rim (8\% - carcinoma de células claras). Em crianças, em ordem decrescente, as metástases estão associadas a casos de leucemia, linfoma, osteossarcoma, rabdomiossarcoma e sarcoma de Ewing. Em casos de metástases em meninges ou extensão direta de neoplasias, os sítios primários envolvem também próstata, linfomas não hodgkinianos e tumores de cabeça e pescoço. Em aproximadamente $25 \%$ dos óbitos encaminhados à necropsia são encontradas metástases no encéfalo, e cerca de $30 \%$ dos adultos e $10 \%$ das crianças com o diagnóstico de neoplasia maligna apresentarão metástases cerebrais durante sua evolução clínica, não havendo predomínio destes tumores em relação ao sexo. Em cerca de $10 \%$ dos casos, os pacientes exibem a metástase cerebral como a forma inicial de apresentação de um tumor de sítio primário desconhecido $(2,9,10,12,13,20)$.

Em menos de $50 \%$ dos pacientes as metástases cerebrais são encontradas sob a forma de um nódulo ovoide, bem delimitado e medindo entre $3 \mathrm{~cm}$ e $5 \mathrm{~cm}$, sendo incomum corresponderem à única lesão metastática do paciente. No restante dos casos são encontrados múltiplos nódulos com diâmetro inferior a $1 \mathrm{~cm}$. Frequentemente as lesões metastáticas exibem focos de degeneração cística, com áreas de edema no tecido adjacente. Microscopicamente correspondem a processos proliferativos bem delimitados, com áreas de necrose e hemorragia, $\mathrm{e}$ ocasionais células neoplásicas infiltrando o neurópilo. A presença de gliose reacional dos tecidos adjacentes é um achado comum. A infiltração do neurópilo pelas células metastáticas usualmente não é tão exuberante quanto o padrão de crescimento sólido ou nodular encontrado junto ao espaço de Virchow-Robin ${ }^{(5,6,11,12,15,17,20,21)}$.

Os sinais e sintomas clínicos das metástases intraparenquimatosas são variados e refletem a destruição localizada do tecido nervoso e do efeito de massa e edema produzido pelas lesões. À avaliação pela ressonância magnética (RM), geralmente as metástases intraparenquimatosas do encéfalo são áreas circunscritas em T1 e T2, com captação difusa ou marginal de contraste, havendo edema do parênquima circunjacente. Os fatores prognósticos envolvidos neste grupo de pacientes incluem idade, sítio primário, presença de metástases em outros sítios anatômicos, sensibilidade do tumor à terapia, status de Karnofsky e número e local das lesões no $\operatorname{SNC}(3-6,17,20)$.

Em geral, as características imuno-histoquímicas das metástases do SNC, principalmente a imunoexpressão dos vários tipos de citoqueratina, são semelhantes ao perfil do tumor primário, tornando este método uma etapa fundamental na classificação histogenética e determinação do sítio primário/origem destes processos, assim como possibilitam a diferenciação entre neoplasias primárias e secundárias $(3,6,7,9,17,20)$. Os autores avaliaram 100 casos de tumores metastáticos intraparenquimatosos do encéfalo a fim de determinar a topografia e os tipos histológicos envolvidos e avaliar o sítio primário destes processos por meio de seu perfil imuno-histoquímico.

\section{Material e método}

\section{Grupo de pacientes}

O presente estudo transversal, analítico e retrospectivo avaliou 100 casos distintos de metástases intraparenquimatosas do encéfalo previamente analisadas no Laboratório de Anatomia Patológica e Citopatologia do Grupo Hospitalar Conceição de Porto Alegre-RS, abrangendo um período de estudo igual a 182 meses (entre abril de 1995 e dezembro de 2009). Os casos selecionados foram inicialmente avaliados no Departamento de Neurocirurgia desta mesma instituição. A pesquisa foi aprovada pelo comitê de ética em pesquisa Grupo Hospitalar Conceição, correspondendo ao número de protocolo 09-206, de janeiro de 2010.

Para cada amostra foram realizados cortes histológicos de 3 micrômetros de espessura, corados por hematoxilina e eosina (HE), para comprovação diagnóstica. Os tumores primários ou que se estendiam por continuidade ao encéfalo foram excluídos do estudo, assim como as metástases que acometiam as meninges intracranianas e os tumores de medula espinhal. Todos os casos foram reavaliados por dois patologistas, individualmente e em conjunto, havendo uma concordância de $97 \%$ entre o diagnóstico prévio e os dados obtidos pelo estudo (razão do teste Kappa igual a $+0,97$ ). Os espécimes consistiam em biópsia estereotáxica, ressecção de lesões nodulares e lobectomias, sendo previamente fixadas em formalina a $10 \%$ e incluídas em parafina. 
Em todos os casos da amostra foram determinados o tipo histológico e a topografia envolvida (previamente designada pela equipe de neurocirurgia), assim como foram submetidos a estudo imuno-histoquímico com o intuito de determinar as suas características por este método e o sítio primário de cada lesão. Os dados obtidos pela avaliação imuno-histoquímica foram então comparados com a informação clínica enviada no momento da intervenção cirúrgica.

\section{Técnica imuno-histoquímica}

De cada espécime foram obtidos cortes histológicos de 3 micrômetros de espessura, os quais foram alocados em lâminas silanizadas. Para proceder à técnica de imunohistoquímica, cada lâmina foi encaminhada para desparafinização do material com o uso de xilol e hidratação dos cortes com etanol. A recuperação antigênica era realizada em forno de micro-ondas, com solução de ácido cítrico $10 \mathrm{mM} / \mathrm{pH}$ 6, em dois ciclos de 9 minutos cada, em potência de $750 \mathrm{~W}$. O bloqueio da peroxidase endógena foi realizado com o uso de água oxigenada a 3\% (10 volumes). O anticorpo primário foi diluído em solução de albumina a 1\% e azida sódica a 0,1\% em solução tampão salina de fosfato (PBS), incubado em câmara úmida, por 30 minutos a $37^{\circ} \mathrm{C}$ e posterior permanência do material em refrigeração a $4^{\circ} \mathrm{C}$ por 18 horas. $\mathrm{O}$ uso de anticorpo secundário biotinilado empregava uma câmara úmida a $37^{\circ} \mathrm{C}$, por 30 minutos, assim como a incubação com o complexo estreptoavidina-biotina-peroxidase (SABP). $O$ substrato cromogênico utilizado correspondia a diaminobenzidina 60 mg\% em PBS, e como contracoloração foi utilizada a hematoxilina de Harrys. Os anticorpos utilizados foram os seguintes (DAKO Corporation, NOVOCASTRA):

- AE1/AE3, 34BETAE12, 35BETAH11, CAM5.2, CK7, CK20, CK19, CK8, vilina, tireoglobulina, fosfatase ácida prostática, PSA, CD10, CD30, PLAP, EMA, CD125, $\mathrm{RE}$, GCDFP, apoproteína do surfactante, RCCMa, TTF-1 e CEA para comprovar diferenciação epitelial;

- melan-A, MART1 e HMB45 para comprovar diferenciação melanocítica;

- LCA, CD3, CD20, CD45RB, CD15, CD30, CD43 e CD79 para comprovar diferenciação hematopoiética;

- MIC2, sinaptofisina, WT1, GFAP, enolase neurônio específica, cromogranina, actina, desmina, CD34, proteína do neuroblastoma e CD99 para excluir tumores primários do SNC e sarcomas.
Para cada caso foram utilizados diferentes anticorpos, que compunham então um painel imuno-histoquímico, sendo que a expressão obtida pelas células neoplásicas pode sugerir o sítio primário da neoplasia, conforme dados já estabelecidos pela literatura. A escolha dos anticorpos dependia das características morfológicas da neoplasia à coloração de HE. O local de acometimento da metástase e o sítio primário foram indicados pela equipe de neurocirurgia.

\section{Teste estatístico}

A análise estatística do estudo foi realizada por meio de tabelas e variáveis descritivas, sendo utilizado o teste do quiquadrado para verificar a associação entre a topografia da metástase e o tipo histológico ou sítio primário da neoplasia. Os resultados foram considerados significativos a um nível de significância máximo de 5\%. Para o processamento e a análise dos dados coletados foi utilizado o software estatístico SPSS versão 17.0.

\section{Resultados}

A idade média correspondeu a $58,7 \pm 16,5$ anos, e a idade mediana correspondeu a 62 anos. Houve 61 casos (61\%) acometendo o sexo masculino e 39 , o sexo feminino (39\%). À coloração de HE, os tipos histológicos encontrados compreenderam o adenocarcinoma ( 56 casos [56\%]) (Figuras 1, 2 e 3), linfoma não hodgkiniano (12 casos [12\%]), neoplasia maligna indiferenciada (nove casos [9\%]), melanoma maligno (oito casos [4,1\%]), carcinoma indiferenciado (sete casos [7\%]), carcinoma epidermoide (cinco casos [5\%]) e neoplasia de células germinativas (três casos [3\%]).

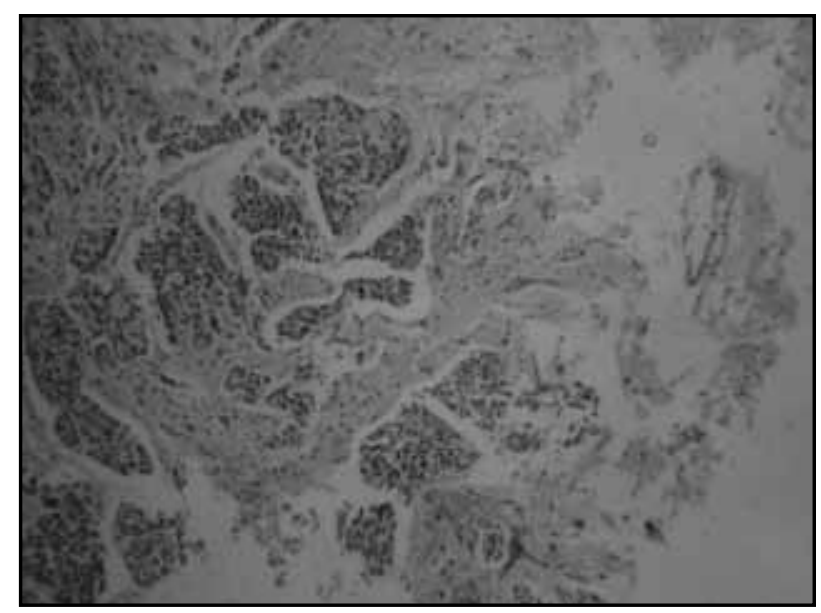

Figura 1 - Metástase de adenocarcinoma de intestino grosso em parênquima cerebral (HE, 40x) 


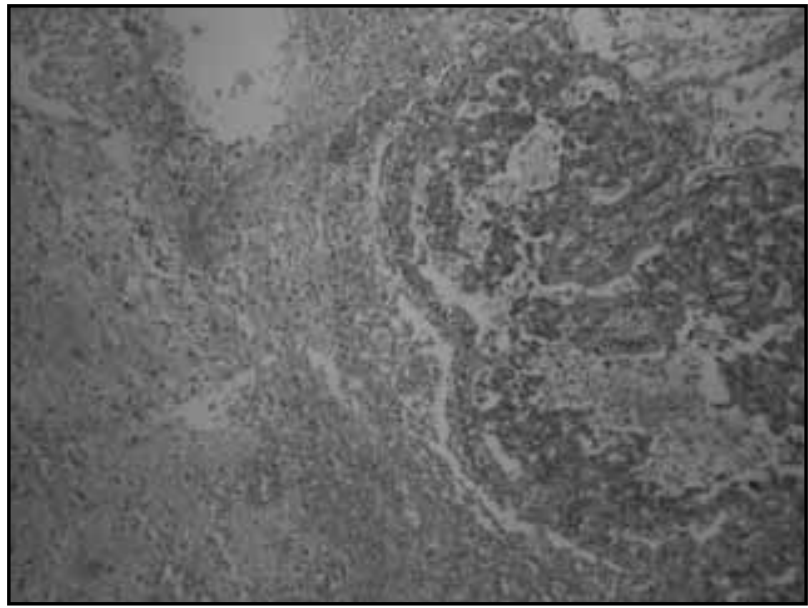

Figura 2 - Metástase de adenocarcinoma de pulmão em parênquima cerebral (HE, 40x)

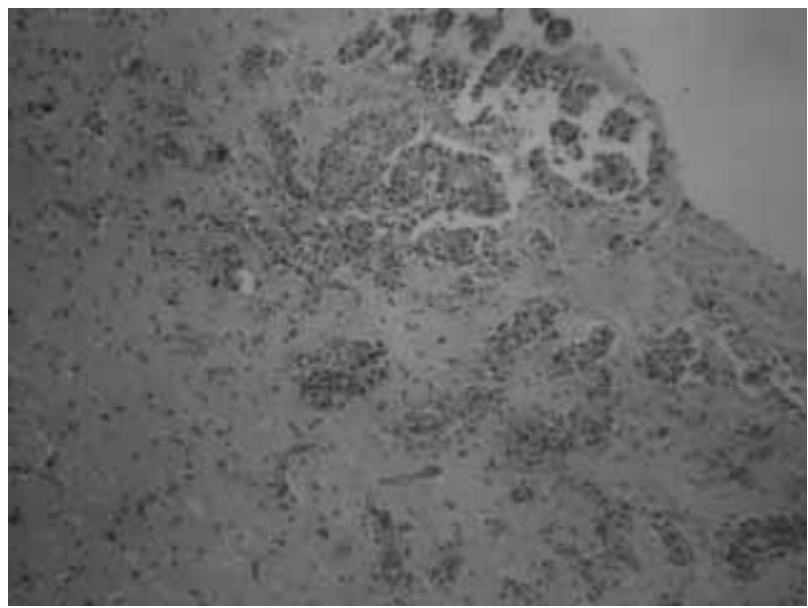

Figura 3 - Metástase de carcinoma ductal de mama em parênquima cerebral (HE, 40x)

As regiões anatômicas envolvidas foram os hemisférios cerebrais (78 casos [78\%]), o cerebelo (15 casos [15\%]), outras regiões da fossa posterior (cinco casos [5\%]) e os ventrículos laterais (dois casos [2\%]).

Os achados do estudo imuno-histoquímico realizado está demonstrado na Tabela 1. Os casos de carcinoma de pulmão classificados como de pequenas células apresentaram imunoexpressão positiva para os anticorpos AE1AE3, CD56, cromogranina e sinaptofisina. A Tabela 2 apresenta os sítios primários envolvidos e os tipos histológicos correspondentes. Foi encontrada concordância de $95 \%$ entre o perfil imuno-histoquímico obtido pelo estudo e a informação clínica do sítio primário. A análise estatística não determinou relação significativa entre o tipo histológico ou o sítio primário e a topografia da metástase $(p=0,125)$.

As neoplasias malignas indiferenciadas (nove casos [9\%]), após o estudo imuno-histoquímico, apresentaram imunofenótipo compatível com carcinoma indiferenciado em seis casos (com provável sítio primário em pulmão e mama), linfoma não hodgkiniano de alto grau em dois casos e carcinoma tireoidiano em um caso.

\section{Discussão}

No encéfalo, as metástases podem ser encontradas nas meninges (cerca de $10 \%$ a $15 \%$ ) ou sob a forma intraparenquimatosa (em torno de 90\%). A maioria dos casos de metástases encefálicas acomete os hemisférios cerebrais ( $80 \%$ aproximadamente), especialmente nas zonas adjacentes às artérias e na junção entre o córtex e a substância branca, sendo os lobos frontal e parietal os mais comprometidos. As metástases são frequentemente encontradas nas áreas de ramificação das artérias cerebrais anterior, média e posterior. Em cerca $15 \%$ dos casos as lesões acometem o cerebelo. Localizações anatômicas menos comuns incluem núcleos da base, tronco encefálico, pineal, plexo coroide e região subependimária. As metástases intraparenquimatosas do encéfalo acometem primariamente adultos e frequentemente correspondem à disseminação sanguínea de um carcinoma. Metástases de sarcomas são raras e ocorrem em frequência inferior em relação à lesão primária. As metástases do melanoma maligno cutâneo se apresentam frequentemente como nódulos múltiplos, enquanto nódulos únicos estão mais associados às metástases de tumores do trato gastrointestinal $\left.\right|^{(1,4,6,12,20)}$.

A idade média dos pacientes do estudo correspondeu a 58,7 anos, não havendo caso de metástases na infância. O adenocarcinoma foi o principal tipo histológico encontrado (56\%), sendo os demais tipos representados por linfoma não hodgkiniano (12 casos [12\%]), neoplasia maligna indiferenciada (nove casos [9\%]), melanoma maligno (oito casos $[4,1 \%])$, carcinoma indiferenciado (sete casos [7\%]), carcinoma epidermoide (cinco casos [5\%]) e neoplasia de células germinativas (três casos [3\%]). Os hemisférios cerebrais foram a região anatômica mais acometida $(78,0 \%)$, seguidos pelo cerebelo (15\%). Não foram encontradas metástases na região selar, na pineal e no plexo coroide. Os dados obtidos em relação aos tipos histológicos envolvidos e às regiões anatômicas mais frequentemente implicadas foram semelhantes àqueles descritos na literatura, que determinam que o tipo histológico mais comum das metástases cerebrais corresponde ao adenocarcinoma ( $70 \%$ a $80 \%$ dos casos), sendo os hemisférios cerebrais ( $80 \%$ dos casos) e o cerebelo (em torno de 10\%) as topografias mais frequentemente envolvidas. As lesões metastáticas que acometem a região selar, a pineal, o plexo coroide e o tronco cerebral são raras, com prevalência inferior a $5 \%$ em conjunto ${ }^{(5,6,13,17,18,20,25)}$. 


\section{Achados imuno-histoquímicos associados ao sítio primário em 100 casos de metástases}

\section{Tabela 1 encefálicas}

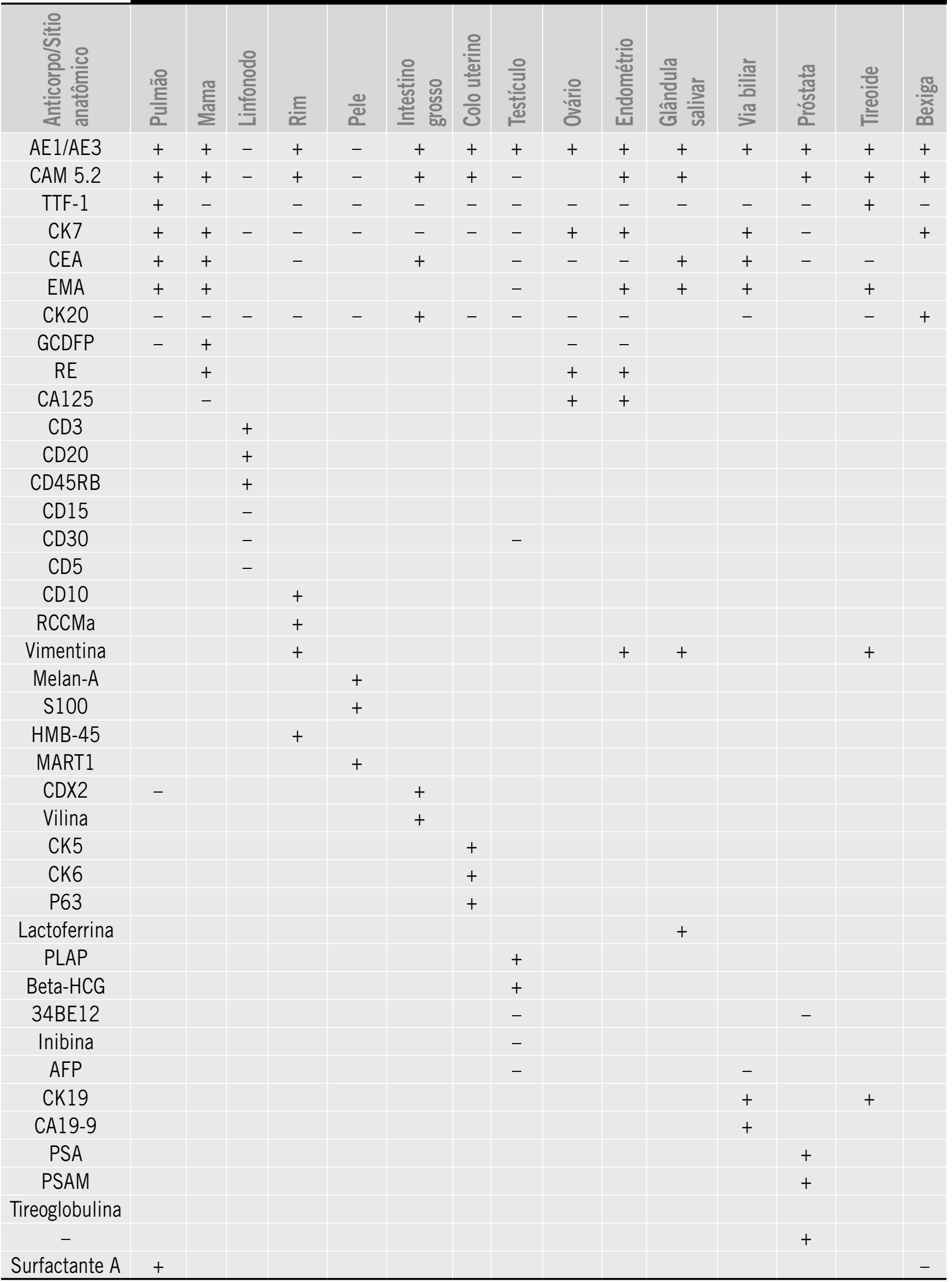


Tipos histológicos associados ao

Tabela 2 sítio primário

\begin{tabular}{|c|c|c|}
\hline $\begin{array}{c}\text { Sítio } \\
\text { Primário }\end{array}$ & $\begin{array}{c}n \\
(\%)\end{array}$ & Tipos histológicos (n) \\
\hline Pulmão & $29 / 29$ & $\begin{array}{c}\text { Adenocarcinoma (25) } \\
\text { Carcinoma epidermoide (2) } \\
\text { Carcinoma de pequenas } \\
\text { células (2) }\end{array}$ \\
\hline Mama & $16 / 16$ & Carcinoma ductal infiltrante \\
\hline $\begin{array}{c}\text { Tecido } \\
\text { hematopoiético }\end{array}$ & $14 / 14$ & $\begin{array}{l}\text { Linfoma não hodgkiniano } \\
\text { difuso de grandes células } \\
\text { B (12) } \\
\text { Linfoma de Burkitt (2) }\end{array}$ \\
\hline Rim & $12 / 12$ & $\begin{array}{c}\text { Carcinoma renal de células } \\
\text { claras }\end{array}$ \\
\hline Pele & $8 / 8$ & Melanoma maligno \\
\hline $\begin{array}{l}\text { Intestino } \\
\text { grosso }\end{array}$ & $7 / 7$ & Adenocarcinoma \\
\hline Colo uterino & $3 / 3$ & Carcinoma epidermoide \\
\hline Testículo & $3 / 3$ & $\begin{array}{l}\text { Seminoma clássico (2) } \\
\text { Cariocarcinoma (1) }\end{array}$ \\
\hline Ovário & $2 / 2$ & Adenocarcinoma seroso \\
\hline Endométrio & $1 / 1$ & Adenocarcinoma \\
\hline $\begin{array}{l}\text { Glândula } \\
\text { salivar }\end{array}$ & $1 / 1$ & $\begin{array}{c}\text { Carcinoma ex-adenoma } \\
\text { pleomórfico }\end{array}$ \\
\hline Vias biliares & $1 / 1$ & Colangiocarcinoma \\
\hline Próstata & $1 / 1$ & Adenocarcinoma \\
\hline Tireoide & $1 / 1$ & Carcinoma folicular \\
\hline Bexiga & $1 / 1$ & Carcinoma urotelial \\
\hline
\end{tabular}

Os carcinomas de origem pulmonar, mamária, cutânea, renal e gastrointestinal correspondem aos sítios primários que mais comumente determinam metástases intraparenquimatosas encefálicas, com freqüências estimadas em $35 \%, 20 \%, 10 \%, 10 \%$ e $5 \%$, respectivamente ${ }^{(3,5,6,9,20)}$. No presente estudo encontramos índices inferiores para as metástases de origem pulmonar, mama e pele, com frequências de $29 \%$, $16 \%$ e $8 \%$, respectivamente. Para os tumores primários do rim e do trato gastrointestinal foi encontrada prevalência de $12 \%$ e $7 \%$, respectivamente, que correspondem a índices maiores que os encontrados na literatura. Não houve casos de metástase de sarcoma no presente estudo. O carcinoma pulmonar é a principal neoplasia associada às metástases encefálicas de sítio primário desconhecido, sendo, em ordem decrescente, o adenocarcinoma, o carcinoma epidermoide e o carcinoma indiferenciado os tipos histológicos mais comuns. A metástase do carcinoma mamário apresenta características que mimetizam o padrão de ductos pequenos, ninhos sólidos e fila indiana do tumor primário. $\mathrm{O}$ adenocarcinoma de origem gastrointestinal exibe características fenotípicas do epitélio intestinal. A metástase do carcinoma renal é caracterizada pela presença de células de citoplasma claro e uniforme e núcleo redondo com nucléolo proeminente dispostas em padrão sólido, papilar, tubular e lobular, este último mimetizando o hemangioblastoma. A metástase do melanoma maligno cutâneo apresenta variabilidade histológica marcada, sendo frequentemente diagnosticada como uma neoplasia indiferenciada pela coloração de $\mathrm{HE}^{(3,5,8,11,14,17,20)}$. Nos casos descritos, houve nove casos com diagnóstico inicial de neoplasia maligna indiferenciada (9\%), sendo que o estudo imunohistoquímico demonstrou serem seis casos de carcinoma indiferenciado compatíveis com sítio primário em pulmão e mama, dois casos de linfoma não hodgkiniano e um caso de carcinoma tireoidiano.

Os aspectos histomorfológicos e os achados imuno-histoquímicos das metástases do SNC são tão diversos quanto os tumores primários deste sítio anatômico. A maioria dos casos de metástases cerebrais de um carcinoma apresenta o mesmo perfil imuno-histoquímico do sítio primário. Eventualmente, astrócitos neoplásicos e não neoplásicos exibem imunoexpressão positiva para os anticorpos AE1/AE3 e CAM5.2 da mesma forma que os carcinomas metastáticos. Mas, ao contrário dos gliomas, os carcinomas metastáticos apresentam imunoexpressão positiva para outras citoqueratinas, como CK7 e CK20(3, 5, 6, 9, 14, 20).

Uma concordância de $95 \%$ foi encontrada entre o perfil imuno-histoquímico das metástases e a informação clínica fornecida pela equipe médica no presente estudo. As neoplasias com sítio primário na mama, pulmão e próstata estiveram associadas aos casos discordantes. $\mathrm{O}$ padrão da imunoexpressão dos anticorpos utilizados em cada caso individualmente é o fator determinante para estimar o sítio primário de uma lesão metastática, de modo que o uso concomitante dos anticorpos CK7, CK20, 34BETAE12, 35BETAH11, CEA, EMA e CAM5.2 constitui uma etapa fundamental desta avaliação. Existe um total de 20 subtipos de citoqueratina, cada um apresentando diferenças quanto ao peso molecular e à imunoexpressão em diferentes tipos tumorais. Para a identificação de lesões metastáticas de sítio primário desconhecido por meio da técnica de imuno-histoquímica, os dois tipos de citoqueratinas mais utilizados são CK7 e CK20. A CK20, de baixo peso molecular, encontra-se normalmente expressa no epitélio 
gastrointestinal e no urotélio. A CK7 pode ser encontrada em tumores primários de pulmão, endométrio, mama e ovário, não sendo geralmente expressa em tumores do trato gastrointestinal. O conhecimento dessa associação é extremamente importante, visto que a expressão positiva para CK20, associada à expressão negativa para CK7, indica probabilidade aumentada de a metástase ter origem colônica, sendo notada essa associação em 75\% a 95\% dos casos. Quando encontrada uma expressão positiva para CK7 e negativa para CK20, as probabilidades de origem desses tumores são maiores, pois essa associação é encontrada em tumores de origem pulmonar, biliar, pancreática, mamária, ovariana e endometrial. Levando em consideração que a maioria das metástases encefálicas é proveniente do pulmão, e que cerca de $85 \%$ dos carcinomas pulmonares são positivos para CK7, o uso de TTF-1, uma proteína de 38 kilodaltons, com frequente expressão em carcinomas de pulmão e tireoide, e a análise da apoproteína surfactante $A$ e $B$ favorecem o diagnóstico de origem pulmonar. A positividade de TTF-1 é de aproximadamente $68 \%$ nos adenocarcinomas e $25 \%$ nos carcinomas pulmonares de células escamosas. A apoproteína A está expressa em $54 \%$ dos adenocarcinomas pulmonares, enquanto a apoproteína B, em $68 \%$ desses

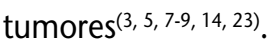

Conjuntamente com a expressão das citoqueratinas CK7 e CK20, alguns anticorpos específicos para determinadas proteínas, como PSA, tireoglobulina, GCDFP, CD10 e CDX2, podem sugerir com maior precisão os tumores de origem prostática, tireóidea, mamária, renal e intestinal, respectivamente. Os adenocarcinomas de origem pulmonar e intestinal podem exibir imunoexpressão positiva para napsin e vilina. O anticorpo GCDFP é derivado de uma proteína comumente encontrada em tumores metastáticos de mama, por se tratar de um marcador de diferenciação apócrina. Ele está expresso em $62 \%$ a $72 \%$ dos casos de carcinoma metastático de mama, embora também o seja por neoplasias de pele, glândula salivar, próstata e vesícula seminal. A imunoexpressão de CEA é comum em casos de carcinoma de pulmão, intestino e mama. A coexpressão de citoqueratinas e vimentina é frequente nos carcinomas de rim, endométrio e tireoide. Melanomas são usualmente positivos para as proteínas $\mathrm{S100}$, HMB-45, melan-A e MART1, raramente havendo positividade para citoqueratinas. Os tumores de células germinativas apresentam imunoexpressão positiva para fosfatase alcalina placentária. Caracteristicamente, os linfomas apresentavam positividade para o anticorpo LCA, o qual determina a linhagem hematopoiética de uma neoplasia, sendo os anticorpos CD3, CD20, CD 30 e CD45RB utilizados, por exemplo, na diferenciação entre linfomas hodgkinianos e não hodgkinianos $(1,8,11,16,18,19,22,24,25)$.

O diagnóstico diferencial de uma lesão metastática deve incluir gliomas de alto grau, oligodendrogliomas anaplásicos, meduloblastomas, neuroblastomas, hemangioblastomas e carcinoma do plexo coroide. A expressão positiva frequente de GFAP, sinaptofisina, proteína do neurofilamento, NeuN e proteína do neuroblastoma é encontrada em lesões primárias do SNC e exclui lesões metastáticas $(3,8,11,15,17,20)$.

\section{Referências}

1. AGUIAR, P. H. et al. Unusual brain metastases from papillary thyroid carcinoma: case report. Neurosurgery, v. 49, p. 1008-13, 2001.

2. BARNHOLTZ-SLOAN, J. S. et al. Incidence proportions of brain metastases in patients diagnosed (1973 to 2001) in the Metropolitan Detroit Cancer Surveillance System. J Clin Oncol, v. 22, p. 2865-72, 2004.

3. BECHER, M. W. et al. Immunohistochemical analysis of metastatic neoplasms of the central nervous system. J Neuropathol Exp Neurol, v. 65, p. 935-44, 2006.

4. BINDAL, R. K. et al. Surgical treatment of multiple brain metastases. J Neurosurg, v. 79, p. 210-6, 1993.

5. CARRIER, D. A. et al. Metastatic adenocarcinoma to the brain: MR with pathologic correlation. AJNR, v. 15, p. 155-9. 1994.

6. CAVENEE, W. K. et al. World Health Organization Classification of Tumors, Tumors of the Nervous System. Pathology \& Genetics, Lyon, IARC, 2007.
7. DENNIS, J. L. et al. Markers of adenocarcinoma characteristic of the site of origin: development of a diagnostic algorithm. Clin Cancer Res, v. 11, p. 376672, 2005.

8. DEYOUNG, B. R. et al. Immunohistological evaluation of metastatic carcinomas of unknown origin: an algorithmic approach. Semin Diagn Pathol, v. 17, p. 184-93, 2000.

9. DRLICEK, M. et al. Immunohistochemical panel of antibodies in the diagnosis of brain metastases of the unknown primary. Pathol Res Pract, v. 10, p. 727-4, 2004.

10. GASPAR, L. et al. Recursive partitioning analysis (RPA) of prognostic factors in three Radiation Therapy Oncology Group (RTOG) brain metastases trials. Int J Radiat Oncol Biol Phys, v. 37, p. 745-51, 1997.

11. GOTTSCHALK, J. et al. The use of immunomorphology to differentiate choroids plexus tumors from metastatic carcinomas. Cancer, v. 72, p. 1343-9, 1993. 
12. GRAVILOVIC, I. T. et al. Brain metastases. J Neurooncol, v. 75 , p. 5-14, 2005.

13. KHUNTIA, D. et al. Whole-brain radiotherapy in the management of brain metastasis. J Clin Oncol, v. 24, p. 1295-304, 2006.

14. MCKENNEY, J. K. et al. Distinguishing metastatic small cell carcinoma (SCC) from a primary cerebellar meduloblastoma (MB) in an adult: an immunohistochemical study of thyroid transcription factor, cytokeratin AE1/3 (AE1/3) and epithelial membrane antigen. J Neuropathol Exp Neurol, v. 59, p. 420, 2000.

15. NEVES, S. et al. Pseudogliomatous growth pattern of anaplastic small cell carcinomas metastatic to the brain. Clin Neuropathol, v. 20, p. 38-42, 2001.

16. OLIVEIRA, A. M. et al. Thyroid transcription factor-1 distinguishes metastatic pulmonary from welldifferentiated neuroendocrine tumors of other sites. Am J Surg Pathol, v. 25, p. 815-9, 2001.

17. PERRY, A. et al. Metastatic adenocarcinoma to the brain: an immunohistochemical approach. Hum Pathol, v. 28, p. 938-43, 1997.

18. ROSER, F. et al. Single cerebral metastasis 3 and 19 years after primary renal cell carcinoma: case report and review of the literature. J Neurol Neurosurg Psychiatry, v. 72, p. 257-68, 2002.

19. SHEFFIELD, M. V. Comparison of five antibodies as markers in the diagnosis of melanoma in cytologic preparations. Am J Clin Pathol, v. 118, n. 6, p. 930-6, 2002.

20. SCHEITHAUER, B. W. et al. Tumors of the Nervous System. Armed Forces Institute of Pathology, vol. 7, series 4, Washington, 2007.

21. TAILIBERT, S. et al. Leptomeningeal metastases from solid malignancy: a review. J Neurooncol, v. 75, p. 85-99, 2005.

22. TIMÁR, J. et al. Molecular pathology of tumor metastasis. Pathol Oncol Research, v. 7, n. 3, p. 217-30, 2001.

23. TRILLET, V. et al. Cerebral metastases as first symptom of bronchogenic carcinoma. A prospective study of 37 cases. Cancer, v. 67, p. 2935-40, 1991.

24. VARADHACHARY, G. R. et al. Diagnostic strategies for unknown primary cancer. Cancer, v. 100, p. 1776-85, 2004.

25. ZACEST, A. C. et al. Surgical management of cerebral metastases from melanoma: outcome in 147 patients treated at a single institution over two decades. J Neurosurg, v. 96, p. 552-8, 2002.

\begin{tabular}{l|l} 
& Endereço para correspondência \\
\hline & Eduardo Cambruzzi \\
& Hospital Nossa Senhora da Conceição \\
& Laboratório de Patologia \\
Av. Francisco Trein, 596-20 andar - & \\
B. Cristo Redentor \\
CEP: $91350-200$ - Porto Alegre-RS \\
Telefax: (51) 3357-2164 \\
e-mail: dudacambruzzi@yahoo.com.br
\end{tabular}

